ARTICLE

Received 9 Sep 2015 | Accepted 30 Mar 2016 | Published 27 Apr 2016

DOI: 10.1038/ncomms11462 OPEN

\title{
Homotypic cell competition regulates proliferation and tiling of zebrafish pigment cells during colour pattern formation
}

\author{
Brigitte Walderich ${ }^{1}$, Ajeet Pratap Singh ${ }^{1}$, Prateek Mahalwar ${ }^{1} \&$ Christiane Nüsslein-Volhard ${ }^{1}$
}

The adult striped pattern of zebrafish is composed of melanophores, iridophores and xanthophores arranged in superimposed layers in the skin. Previous studies have revealed that the assembly of pigment cells into stripes involves heterotypic interactions between all three chromatophore types. Here we investigate the role of homotypic interactions between cells of the same chromatophore type. Introduction of labelled progenitors into mutants lacking the corresponding cell type allowed us to define the impact of competitive interactions via long-term in vivo imaging. In the absence of endogenous cells, transplanted iridophores and xanthophores show an increased rate of proliferation and spread as a coherent net into vacant space. By contrast, melanophores have a limited capacity to spread in the skin even in the absence of competing endogenous cells. Our study reveals a key role for homotypic competitive interactions in determining number, direction of migration and individual spacing of cells within chromatophore populations.

\footnotetext{
${ }^{1}$ Max Planck Institute for Developmental Biology, Spemannstrasse 35, 72076 Tübingen, Germany. Correspondence and requests for materials should be addressed to C.N.-V. (email: christiane.nuesslein-volhard@tuebingen.mpg.de).
} 
C olour patterns are widespread in the animal kingdom and not only protect against harmful radiation, but also serve as recognition signals in intra- and interspecies communication. The zebrafish, Danio rerio, has emerged as the vertebrate model organism to study the mechanisms underlying colour pattern formation ${ }^{1-4}$. The characteristic pattern of alternating horizontal dark and light stripes represents a system of three different pigment-cell types distributed in superimposed layers in the skin. In the dark stripes, black melanophores are covered by a middle layer of blue iridophores and a thin top layer of yellow xanthophores. In the light stripes, a compact layer of xanthophores covers silvery iridophores.

The adult pigmentation pattern is formed during metamorphosis, a period between $\sim 3$ and 6 weeks of development. Iridophores and melanophores are derived from stem cells located at the segmentally reiterated dorsal root ganglia (DRG) of the peripheral nervous system ${ }^{5-7}$. Iridophores emerge in the skin along the horizontal myoseptum; they proliferate and spread as densely connected cells forming the first light stripe. They spread further, dorsally and ventrally, as a loose net of cells into the regions where the dark stripes will form and then again undergo patterned aggregation to form new light stripes ${ }^{5}$. Melanoblasts migrate and proliferate along the peripheral neurons innervating the skin and emerge in situ in the skin where they differentiate and expand to fill in the dark stripes ${ }^{5-7}$. Most adult xanthophores arise from larval xanthophores, which begin to divide at the onset of metamorphosis and cover the entire body of the fish ${ }^{8,9}$.

While each pigment-cell type is distributed in a single cell wide layer, xanthophores and iridophores display different morphologies depending on their position in the pattern: in the dark stripes stellate xanthophores form a net-like structure and loose iridophores appear blue, whereas densely packed, silvery iridophores are tightly associated with compact xanthophores in the light stripes ${ }^{8,10-12}$. The establishment of organized cell morphologies indicates close cell-cell communication between skin layers, and is essential for the sharpness and brightness of the striped pattern.

Mutants lacking one or more of the pigment-cell types are not able to produce the striped pattern correctly (for example, nacre (encoding Mitfa) mutants that lack melanophores, pfeffer/fms (encoding Csf1rA) mutants that lack xanthophores, and shady (encoding Ltk), rose (encoding Ednrb1Ba) and transparent (encoding Mpv17) mutants where iridophores are absent or strongly reduced $)^{13-17}$. In all these cases the two remaining chromatophore types form an irregular, residual striped pattern. Supplementing the missing cell type in chimeric animals obtained by blastula transplantations can locally restore a normal pattern $12,17,18$. This indicates that heterotypic interactions between the three cell types are required to form a normal pattern. Analyses of mutants lacking one of the pigment-cell types, as well as ablation experiments, have suggested the presence of several attractive and repulsive signals between chromatophores, which act over long or short ranges during stripe formation ${ }^{12,19,20}$. In the absence of xanthophores, melanophore numbers are reduced, stripes break up into spots, and ectopic melanophores remain scattered in the light stripe region. In iridophore mutants, the number of melanophores is also strongly reduced, and only the first two dark stripes form broken into spots ${ }^{5,12}$. In the absence of two pigment-cell types, remaining iridophores (in nacre; pfeffer mutants) and xanthophores (in shady; pfeffer) cover the flank of the fish, whereas the melanophores in the absence of iridophores and xanthophores (shady; pfeffer) are reduced in number and scattered in lower than normal density ${ }^{12}$. These observations indicate a strong dependence of melanophore survival on interactions with the other cell types, whereas iridophores and xanthophores display a more autonomous behaviour.

Previous analyses of chimeras generated between wild type and mutants lacking one of the three cell types placed emphasis on the interactions among different pigment cells (heterotypic interactions) ${ }^{12,18}$. The role of homotypic interactions (between cells of the same type) remains poorly understood. In vitro observations of interactions between isolated pigment cells did not uncover any obvious response between cells of the same type, although an interaction response between melanophores and xanthophores has been detected ${ }^{21}$. Genetic analyses also have suggested that homotypic interactions exist among melanophores and xanthophores ${ }^{18,22}$. Here, we analyse the cell-level outcome of the homotypic interactions among the chromatophores in vivo through the generation of chimeric animals, and we corroborate our findings with results from regeneration experiments. We investigate the proliferation and spread of labelled chromatophore clusters in the presence or absence of endogenous cells within a layer. For all pigment-cell types, we observe an increase in the average size of clusters in environments lacking the respective cell type. This indicates that there is competition between pigment cells during normal development. Xanthophores and iridophores have an intrinsic tendency to proliferate and evenly fill the space in the skin, whereas melanophores have only a restricted potential to proliferate and spread in the skin. In addition, our observation that clusters of all three pigment-cell types filled the chromatophore-devoid region in their neighbourhood as coherent nets with normal density (rather than dispersing uniformly into all available vacant space), suggests that there are contact dependent homotypic interactions between chromatophores. In all cases, donor-derived chromatophores locally restored the organization of the host chromatophores, which resulted in a normal pattern. We conclude that, whereas changes in pigment-cell morphologies during stripe formation are regulated by heterotypic interactions ${ }^{22,23}$, pigment-cell proliferation and dispersal in the skin are predominantly regulated by homotypic competition.

\section{Results}

Blastomere transplantations. We transplanted a small number of blastomeres to obtain single-labelled pigment-cell progenitors in wild type or mutant embryos. Using appropriate markers, we selected chimeric individuals for the presence of small clusters of donor-derived pigment cells at larval stages (5 days post fertilization (dpf)) or at the onset of metamorphosis (21 dpf) and traced their progeny to adulthood. Blastomere transplantations between wild-type embryos resulted in clusters of pigment cells that resemble Cre-induced clones ${ }^{5}$ in shape and size, indicating that frequently a single progenitor cell had given rise to the clusters, and that in many cases the clusters were clonal. In experiments that allowed us to follow more than one type of pigment cell it became apparent that in most cases the donor cells gave rise to multipotent neural crest progenitors of all three cell types.

Homotypic interactions among xanthophores. The dynamics of xanthophore morphogenesis during stripe formation has been described previously ${ }^{8}$. To specifically track the xanthophores in normal development, chimeric animals were created by transplantation of cells from transgenic $\operatorname{Tg}(\text { pax } 7: G F P)^{8,24}$ blastula stage embryos into wild-type or albino hosts (Fig. 1a,d). In albino (Fig. 1d) melanophores are unpigmented ${ }^{25}$, allowing for better visibility of donor-derived labelled xanthophores and pigmented melanophores. We followed the pattern development of individual 

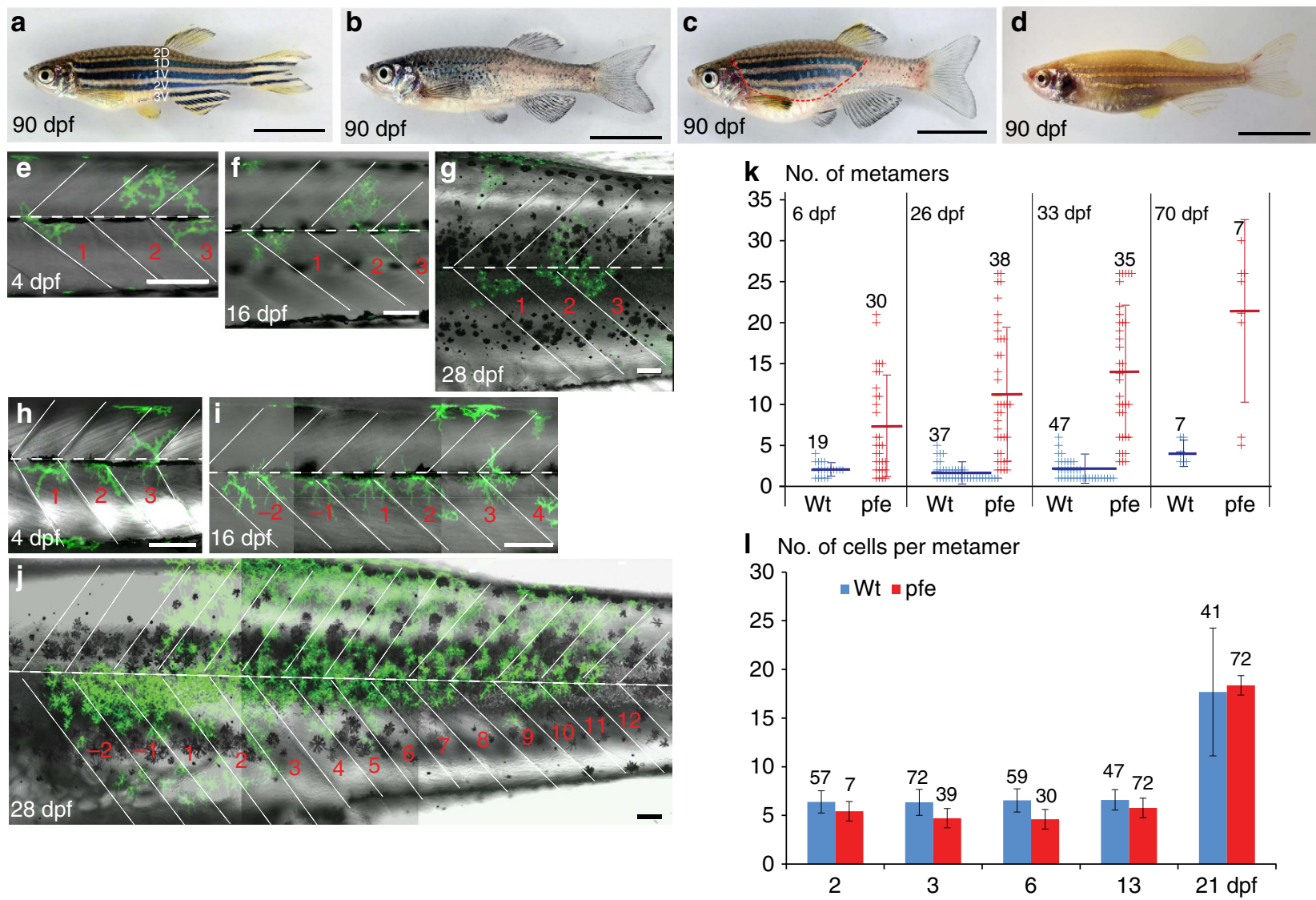

Figure 1 | Development of xanthophore clusters in wild type and pfeffer. (a-d) Stripe pattern in 3-month-old (a) wild-type zebrafish, (b) pfeffer mutant, (c) chimera obtained by blastomere transplantation of wild type ( $\operatorname{Tg}($ pax $7: G F P)$ ) into pfeffer; the area with donor xanthophores is demarcated by a red dashed line and (d) control (albino). In (a) the dark stripes nomenclature is depicted along the dorsoventral axis. Developmental profile of Tg(pax7:GFP)labelled wild-type xanthophores (green) in a (e-g) control and (h-j) pfeffer chimera. Dashed white lines-vertical and horizontal myosepta. Scale bars, $\mathbf{a}-$ $\mathbf{d}=1 \mathrm{~cm} ; \mathbf{e}-\mathbf{j}=100 \mu \mathrm{m}$. (k) Quantification of the number of metameres spanned by xanthophore clusters at larval stage ( $6 \mathrm{dpf})$ (wild type, $n=19 \mathrm{clusters,}$ 12 fishes; pfeffer, $n=30$ clusters, 18 fishes; $P \leq 0.0001$ ); $26 \mathrm{dpf}$ (wild type, $n=37$ clusters, 10 fishes; $p f e f f e r, n=38$ clusters, 17 fish; $P \leq 0.0001$ ); 33 dpf (wild type, $n=47$ clusters, 10 fishes; pfeffer, $n=35$ clusters, 17 fishes; $P<0.0001$ ); $70 \mathrm{dpf}$ (wild type, $n=7$ clusters, 4 fishes; pfeffer, $n=7$ clusters,

7 fishes; $P=0.0077$ ). The horizontal lines in dark blue (wild type) and red (pfeffer) indicate the mean value and the error bars represent standard deviation. We show that the differences between albino and pfeffer are significant at all time points investigated by using Student's $t$-test (Welsh corrected). (I) Number of xanthophores per metamere in wild type (blue) and pfeffer transplants (red). Numbers of metameres analysed are depicted in the graph, error bars represent standard deviation. No significant differences between wild-type fish (blue) and pfeffer transplants (red) according to Student; $t$-test (Welsh corrected) were found for $2 \mathrm{dpf}: P=0.1795$ and $21 \mathrm{dpf}: P=0.6123$. Overall $3 \mathrm{dpf}(P=<0.0001), 6 \mathrm{dpf}(P=<0,0001)$ and $13 \mathrm{dpf}(P=0.0042)$ were shown to be significantly different.

fish with small clusters of $1-5$ xanthophores in larvae $(<5 \mathrm{dpf})$ from the onset of metamorphosis until $70 \mathrm{dpf}(n=47$ xanthophore clusters in 12 fishes) (Fig. 1e-g; Supplementary Fig. 1). Numbers of donor-derived xanthophores in the clusters remained constant during larval stages ${ }^{8}$. At the onset of metamorphosis between 16 and $20 \mathrm{dpf}$, the xanthophores began to divide as did the host xanthophores ${ }^{8}$. Subsequently the clusters spanned over 1-4 adjacent metameres (Fig. 1k) and across several light and dark stripes along the dorsoventral axis (Supplementary Fig. 1). The rate of division was variable between different clusters, averaging about one cell division per 10 days, as was previously observed in non-chimeric fish ${ }^{8}$. Labelled xanthophore clusters consisted of more or less loosely connected cells.

pfeffer mutants lack xanthophores in adults (Fig. 1b) ${ }^{18}$. The introduction of xanthophore progenitors into pfeffer hosts can lead to large patches of stripe rescue in chimeric animals indicating that xanthophores have the ability to divide rapidly and to spread into vacant space ${ }^{18}$ (Fig. 1c). We analysed xanthophore clusters in chimeras obtained by transplantation of $\operatorname{Tg}($ pax7:GFP) blastomeres into pfeffer mutant host embryos.
The donor-derived xanthophores, in contrast to xanthophore clusters in wild-type hosts (Fig. 1h-k), already divided during larval stages and occupied larger areas in the skin during metamorphosis. The numbers of segments occupied by xanthophores in pfeffer hosts continually increased starting in larval stages (Fig. 1k). The analysis of pfeffer chimeras ( $n=38$ clusters of xanthophores in 18 fishes) revealed that the clusters spread on average over 6 metameres during larval stages (by $6 \mathrm{dpf}$ ) and by the age of $70 \mathrm{dpf}$ they had spread over 21 metameres (Fig. 1k). Comparing the number of xanthophores per metamere in wild-type fish and pfeffer chimeras (Fig. 1l) revealed that the donor-derived xanthophores eventually fully restored the xanthophore number. This indicates that in normal development competition between xanthophores limit their rate of proliferation and spreading. Recently, it has been suggested that xanthophore proliferation and differentiation is triggered by thyroid hormone stimulation at the onset of metamorphosis?. Our data indicate that the reduction in xanthophore cell density is the critical cue that alone can trigger xanthophore proliferation. 
Closer analysis revealed that the donor-derived xanthophores divided rapidly in the pfeffer hosts at a rate of more than two cell divisions per 10 days, and spread in all directions, most commonly along the myosepta both horizontally and vertically (Fig. 2a-c,d,e). The xanthophores at the border of the clusters collectively migrated into neighbouring regions devoid of xanthophores, thus increasing their coverage (Fig. 2d,e). In several cases individual clusters fused and covered the fish completely. When donor xanthophores encountered host iridophores in the light stripe, they changed in shape to become compact (as in wild type) (Fig. 2c). In pfeffer mutants, melanophores form small spots; however, when they encountered donor xanthophores, the melanophores increased in number and locally restored the striped pattern through local migration out of the light stripe region and accumulation in the dark stripe region (Fig. 2f-k). Ectopic melanophores in the mutant areas devoid of xanthophores disappeared on arrival and compaction of donor-derived xanthophores (Fig. 2f-k).

Our observations show that donor-derived xanthophores, in the absence of residual xanthophores in pfeffer hosts, begin to proliferate during embryonic stages. We confirmed this through live-imaging of xanthophore behaviour in both wild type and pfeffer chimeras during late embryogenesis at 48-60 hpf; (Fig. 3; Supplementary Movies 1-3). Xanthophores in wild-type environments extended dynamic filopodia that allowed them to contact and continually probe each other (Fig. 3a-f: filopodial retraction-yellow arrow, filopodial extension-red arrow; Supplementary Movie 1). Similarly, donor-derived xanthophores rarely changed their location or underwent cell division when transplantated into wild-type embryos (Supplementary Movie 2). In contrast, donor xanthophores in pfeffer hosts underwent cell divisions (arrowheads in Fig. 3g-1) and extended dynamic filopodia (arrows in Fig. 3g-l) to explore their environment, and they moved into regions devoid of xanthophores (Fig. 3g-l; Supplementary Movie 3).

To test if the absence of xanthophores in pfeffer can also influence melanophore spreading, we transplanted wild-type cells labelled with $\operatorname{Tg}($ pax7:GFP) into pfeffer; brass mutants, which lack xanthophores and have unpigmented melanophores ${ }^{26,27}$. This allows a clear distinction between donor- and host-derived xanthophores and melanophores. Melanophore clusters did not spread farther than 4 metameres (see below), whereas the xanthophores spread along the anterior-posterior (AP) axis as described above (Fig. 2l). This suggests that the spreading is cell-specific to xanthophores rather than a general property of the pfeffer mutation.

These results indicate that the proliferation rate of xanthophores is regulated by competitive homotypic interactions. The xanthophores expand in areas devoid of xanthophores by cell proliferation and by short-scale cell movement. In hosts lacking xanthophores the donor-derived clusters expand in all directions as a coherent net, maintaining normal distances and close contact between cells, rather than dispersing into the space devoid of xanthophores. This indicates mutual interaction and attraction between xanthophores.

Homotypic interactions among melanophores. We analysed the melanophores in normal development using the dark melanin pigmentation, lacking in albino recipient fish, as a marker (Fig. 4a). Transplantation of blastomeres labelled with $\mathrm{Tg}(\beta a c t: G F P)$ into albino hosts yielded 22 melanophore clusters in nine fishes, which were followed into adulthood. Along the AP axis the clusters spread 2-4 segments on average. At the margins of the cluster, the donor-derived black melanophores intermingled with the unpigmented melanophores of the host. Clusters of donor-derived melanophores contributed to several dark stripes along the dorsoventral body axis as described before ${ }^{6}$ (Supplementary Fig. 2). Melanophore clusters in a number of cases (7/28) contributed to all four stripes including the scales, and dorsal and anal fins, whereas 16 clusters contributed to between 1-3 stripes at the age of 3 months (Supplementary Fig. 4). Four clusters of melanophores appeared exclusively in the caudal fins of the fish. These observations are consistent with the known behaviour of melanophores and their origin in a wild-type context.

Blastomere transplantation into nacre ${ }^{13}$ allowed us to track melanophores in the absence of endogenous melanophores (Fig. 4b). A total of 57 clusters of black, donor-derived melanophores were followed in 20 nacre fishes up to 3-4 months. As observed in the control (albino) chimeras, the donor-derived melanophores contributed to several dark stripes along the dorsoventral body axis (Fig. 4c; Supplementary Fig. 3). In 6 cases out of 57, we found melanophore clones contributing to all four dark stripes as well as pigmentation in scales and anal and dorsal fins. The clusters on the body, although larger than in wild-type chimeras (albino; Fig. 4a), remained restricted along the AP body axis, spanning 6 metameres on average (Fig. 4c-e), which is not statistically different from wild-type (albino) transplants. As observed previously ${ }^{12,17,18}$, in nacre, the stripes were completely restored in chimeric areas, with a dense sheet of donor-derived melanophores, strictly separated from light stripe regions (Fig. 4c). Intriguingly, clusters started shrinking after $35 \mathrm{dpf}$ and by 4 months, $64 \%$ of all clusters in albino, and $33 \%$ of the clusters in nacre disappeared (Fig. 5, cluster in nacre). The reason for the late death of donor melanophores in chimeras is unknown. It suggests that in the chimeras the stem cells providing a regular replacement of melanophores have not been maintained.

In nacre transplants, a series of larval melanophores on the ventral ( $30 \%$ of all clusters) and the dorsal side $(24 \%$ of all clusters) of the fish were frequently observed (Fig. 5a-g). These clusters spanned on average 12 metameres and were present from early larval stages through $35 \mathrm{dpf}$ when they started to disappear (Fig. 4d). Figure 5 shows an example of the development of melanophore clusters, labelled with $T g$ (TDL358:GFP; sox10:mRFP) in nacre. $T g(T D L 358: G F P)$ labels iridophores, whereas $\operatorname{Tg}(\operatorname{sox} 10: R F P)$ labels all neural crest-derived tissue. On $13 \mathrm{dpf}$, streaks of larval melanophores were present both dorsally and ventrally (Fig. 5a), and a confocal scan on the same time point shows the presence of a sox10:mRFP-labelled DRG (Fig. 5b). At $27 \mathrm{dpf}$ adult red fluorescent protein (RFP)labelled melanophores appeared flanking the horizontal myoseptum (Fig. 5c,d), along with donor-derived xanthophore and iridophore clusters (Fig. 5d). At $35 \mathrm{dpf}$ the first dark stripes 1 dorsal (D) and 1 ventral (V) were formed (Fig. 5e). In contrast to the melanophore cluster that spreads over 6 metameres, the xanthophore and iridophores clusters remained restricted to 1-2 metameres (Fig. 5f). On $58 \mathrm{dpf}$ the larval melanophore streaks on the dorsal and the ventral side started to disappear, whereas the melanophores in stripes $1 \mathrm{D}$ and $1 \mathrm{~V}$ persisted (Fig. 5g). At $83 \mathrm{dpf}$ all melanophores have disappeared leaving empty areas between intact light stripes (Fig. 5h).

In summary, we observe that host melanophores have little influence on the dispersal of donor-derived melanophores, and that, in contrast to xanthophores, melanophore clusters in the adult pattern rarely spread laterally over more than six segments. Instead, donor-derived melanophores remain together, and form prominent stripes of normal melanophore density despite being surrounded by regions devoid of melanophores. This indicates that in the absence of residual melanophores, an increased number of melanophores reach the skin, and that melanophores attract each other. 

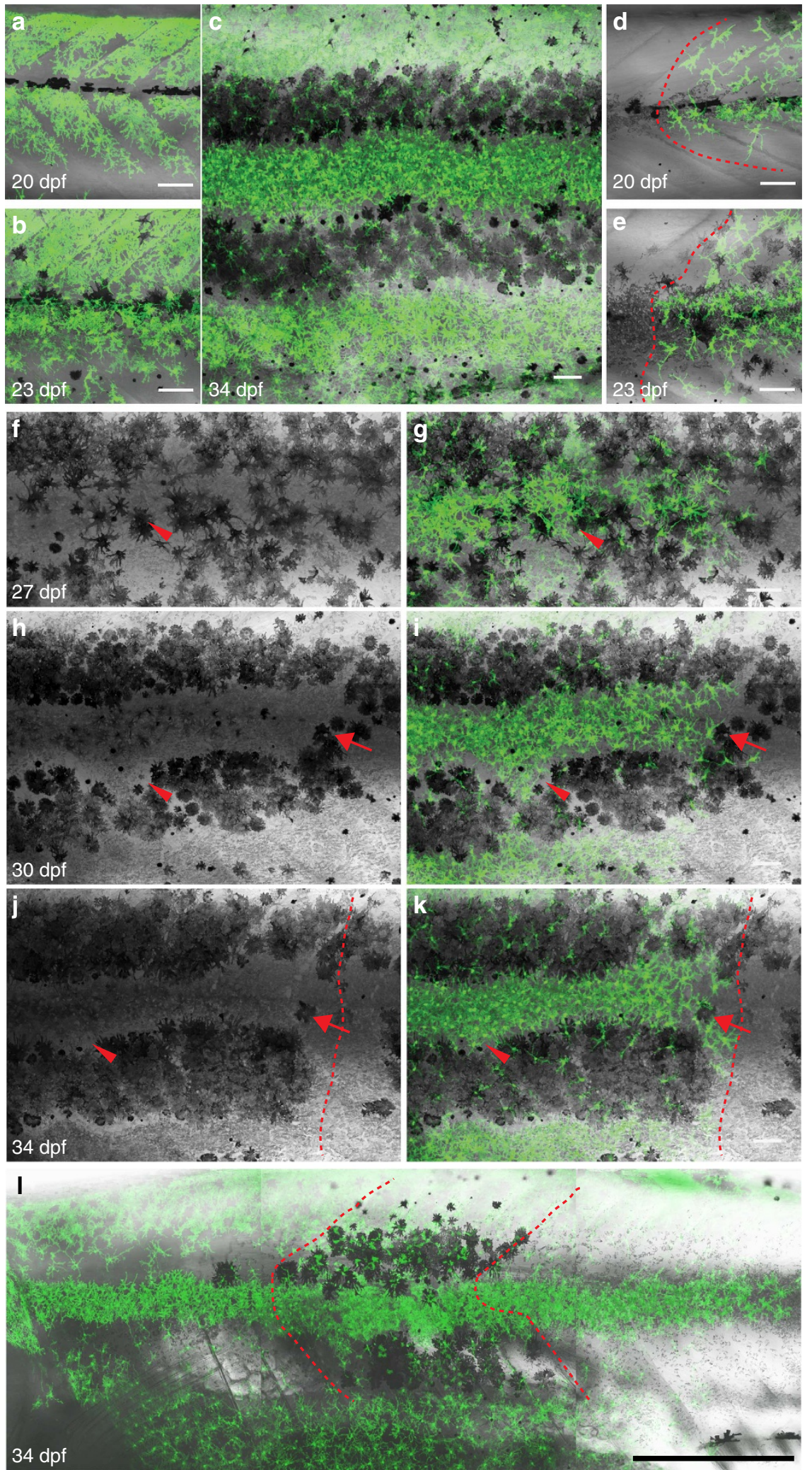

Figure 2 | Local rescue of xanthophore numbers and organization by xanthophores in pfeffer hosts. (a-c) Restoration of normal number and organization of xanthophores in pfeffer. (d,e) Xanthophores spread into neighbouring xanthophore-devoid segments as coherent net. Dashed red line: border of transplanted cluster. (f-k) Restoration of the striped pattern by interactions between the xanthophore cluster and the host melanophores.

(f-k) Widely distributed melanophores (black) become organized into stripes on increase in number of xanthophores and their compaction in the light stripe region. Red arrow: a cluster of melanophores that is cleared over time; red arrowhead: xanthophores retracting from dark stripe region. Dashed red line: border of the cluster showing xanthophores-positive area with rescued pattern on the left, no rescue on the right. (I) Chimera obtained by transplantation of $\operatorname{Tg}$ (pax7:GFP) into pfeffer;brass. The xanthophore cluster covers 17 metamers, whereas the melanophores cluster covers 4 metamers. Xanthophores-green, $\operatorname{Tg}($ pax7:GFP). Dashed red line: border of melanophores cluster. Scale bars, a-k: $100 \mu \mathrm{m}, \mathbf{I}: 250 \mu \mathrm{m}$. 

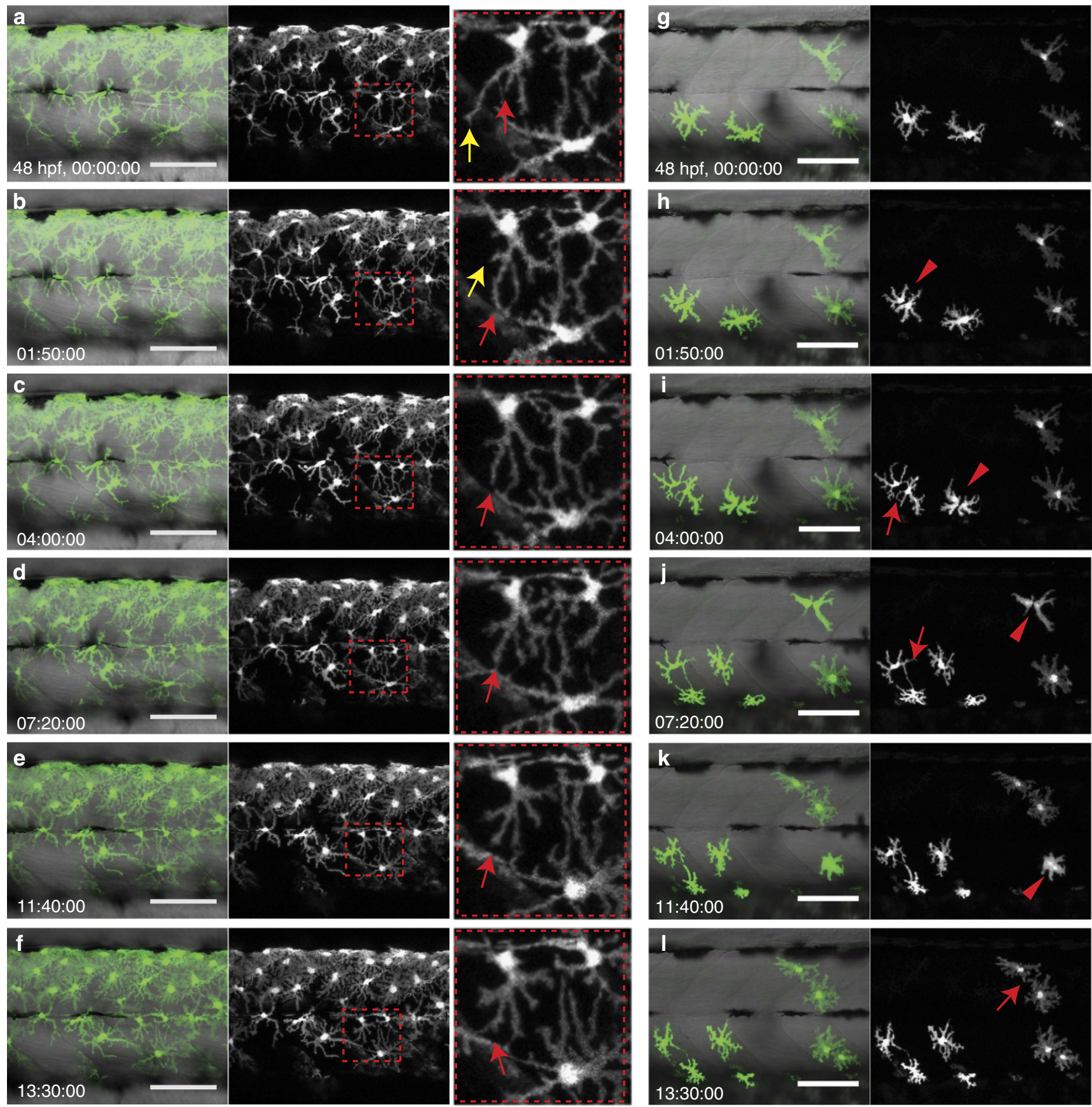

Figure 3 | Interaction of xanthophores in larval stage. (a-f) Live-imaging of wild-type xanthophores-green; $\operatorname{Tg}($ pax7:GFP), shows that cell numbers remain constant during larval development. (Same images in grey scale). Magnification of red dotted boxes: dynamic cell-cell contacts occur by extension (red arrows) and retraction (yellow arrows) of filopodia. (g-I) Live-imaging of xanthophores-green; $T g$ (pax7:GFP) in pfeffer chimera. Transplanted xanthophores divide, for better visibility same image in grey scale (red arrowheads) and extent filopodia to each other (red arrow). Scale bars, a-I: $100 \mu \mathrm{m}$.

Homotypic interactions among iridophores. The labelling of donor cells with $\operatorname{Tg}(\beta a c t: G F P)$ allowed the simultaneous detection of iridophore- and melanophore clusters in chimeric animals in albino hosts (Fig. 6a-c). Iridophore clusters displayed a dorsoventral orientation contributing to several light stripes, much like the Cre-induced Sox 10 clones previously analysed ${ }^{5}$. In these chimeras progenitors of melanophores as well as iridophores have been transplanted. Transplanting $\operatorname{Tg}(T D L 358: G F P$; sox10:mRFP) into wild-type hosts revealed that iridophore clusters begin divisions after the onset of metamorphosis (19-21 dpf). They formed the first light stripe together with the xanthophores (Fig. 6d-g). We followed six clusters through metamorphosis until $40 \mathrm{dpf}$, showing that the clusters spread over 1-4 metamers and the cell number of the clusters increased from 1-2 cells up to 300 cells within 17 days, which represents a doubling of cell numbers every 3-4 days.

Due to low survival rates of shady chimeras, only few clusters of iridophores developing in the shady mutant ${ }^{16}$, which lack adult iridophores, could be followed over longer time periods. In the absence of host iridophores, donor-derived iridophores were able to spread laterally, in one case the cluster spanned 10 metameres at $35 \mathrm{dpf}$, which was never observed in wild type (Fig. 6h-1). This clone showed around 600 mature iridophore cells, whereas iridophore clones in wild type had only around 100 cells at the same time point. 

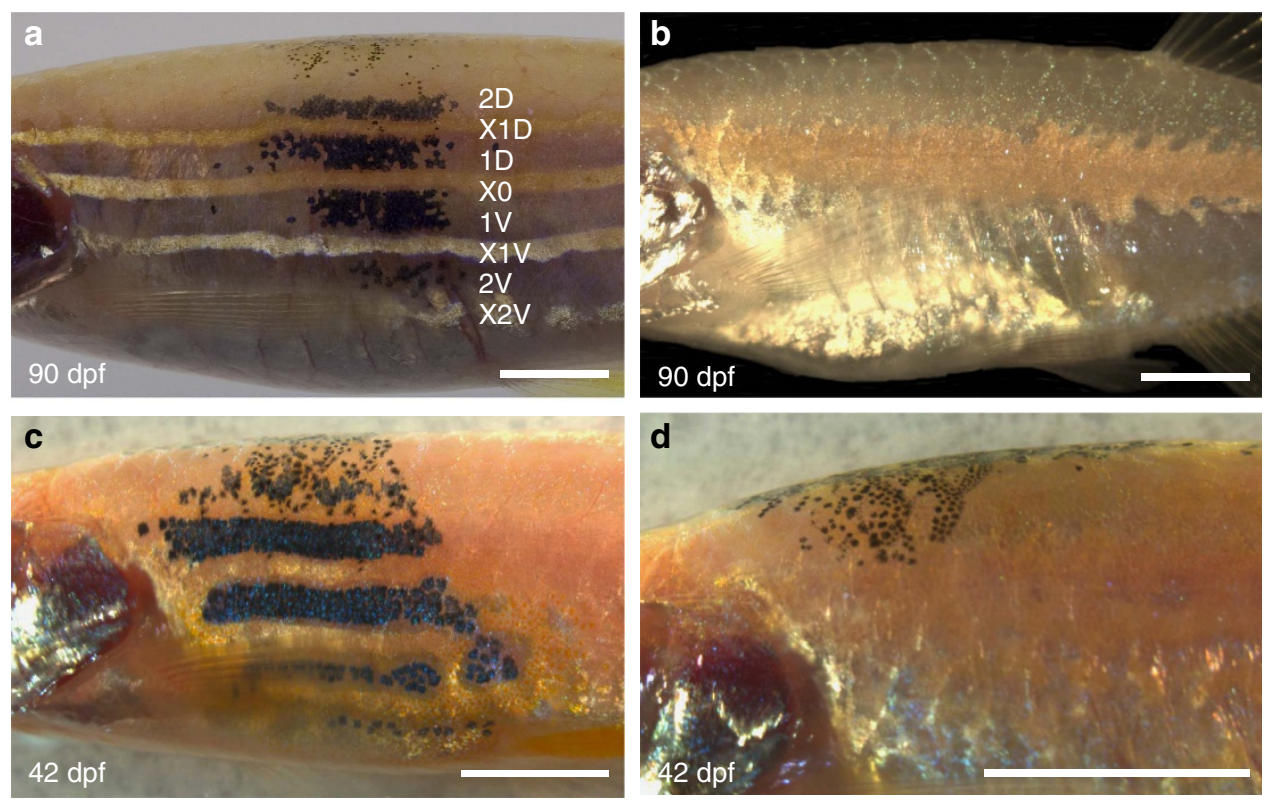

\section{e}

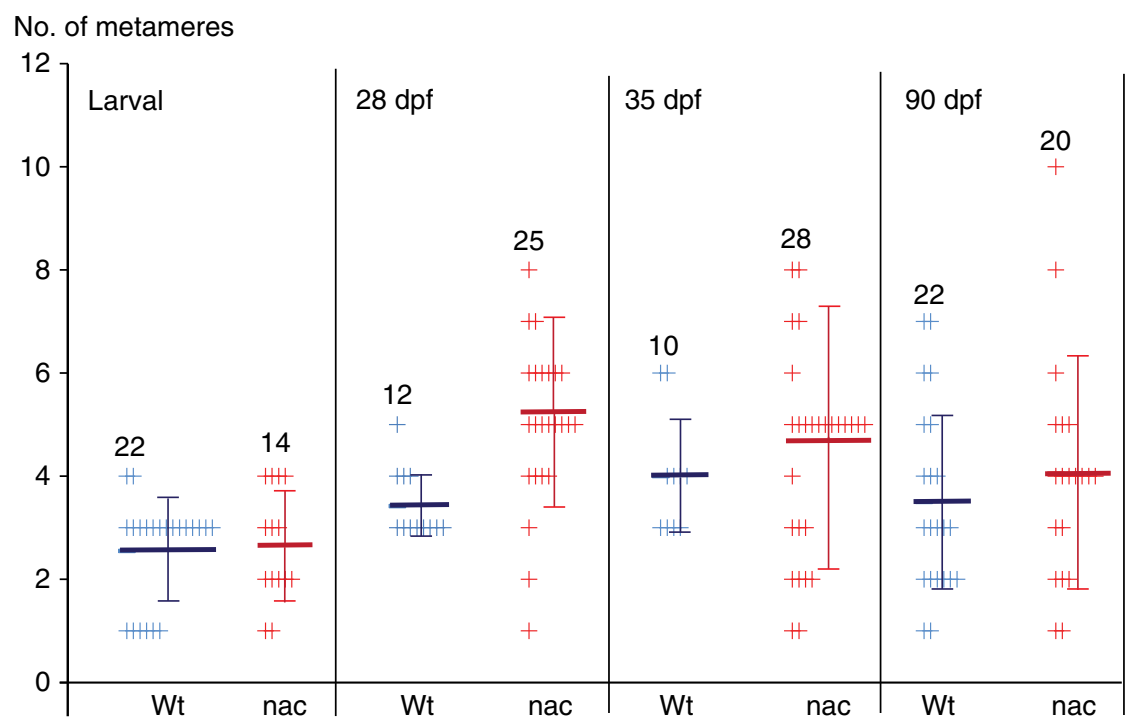

Figure 4 | Transplanted melanophore clusters in control (albino) and nacre chimeras. The organization of wild-type melanophores (black) in (a) albino and (c,d) nacre hosts. Adult nacre fish lacking melanophores (b). Scale bars, a-d: $250 \mu \mathrm{m}$. (e) Quantification of the number of metamers occupied by wild-type melanophores in the body stripes in albino control (blue) and nacre (red) hosts. The number of clusters analysed is depicted in the graph. Student's t-test (Welsh corrected) revealed significant differences between the size of wild type and nacre melanophore clusters at $28 \mathrm{dpf}$ : (wild type, $n=12$ clusters, 7 fishes; nacre, $n=25$ clusters, 17 fishes, $P \leq 0.0002$ ), at larval stages: (wild type, $n=22$ clusters, 10 fishes; nacre, $n=14$ clusters, 20 fishes, $P=0.7892$ ), 35 dpf: (wild type, $n=10$ clusters, 6 fishes; nacre, $n=28$ clusters, 17 fishes, $P=0.2512$ and adult ( $>90$ dpf): (wild type, $n=22$ clusters, 9 fishes; nacre, $n=20$ clusters, 17 fishes, $P=0.3840$ ) no significant difference could be shown. Horizontal lines in dark blue (wild type) and red (nacre) indicate the mean value and the error bars represent standard deviation. Student's $t$-test (Welsh corrected) was used to determine the $P$-value.

Regeneration of chromatophores after stem cell depletion. Analysis of homotypic interactions among iridophores was hampered by a low survival rate of shady chimaeras. Other iridophore mutants, such as rose and transparent, have residual iridophores and hence are not suitable for our analysis. To obtain more information on the autonomous behaviour of iridophores and melanophores, we disrupted the formation of melanophore and iridophore stem cells by inhibiting the erb-b2 receptor tyrosine kinase (ErbB) pathway. ErbB signalling is required to establish the DRGs during the migration of neural crest cells in the early embryo ${ }^{6,28}$. To reduce ErbB3 activity in a temporally controlled manner, we used the small molecule inhibitor
PD168393 at a concentration that results in the absence of several of the DRG-located stem cells of melanophores and iridophores causing gaps in the striped pattern ${ }^{6,28}$. This allowed us to study the behaviour of surviving iridophores and melanophores during the regeneration of the striped pattern in the gaps.

In many of the drug-treated fish, gaps in the striped pattern were observed at $21 \mathrm{dpf}$ : they displayed regions with a reduced number of larval melanophores, and absence of dense iridophores forming the first light stripe at the horizontal myoseptum extending between 3 and 12 metameres (Fig. 7a,f; Supplementary Fig. 5). Fish with gaps in the stripes were followed 

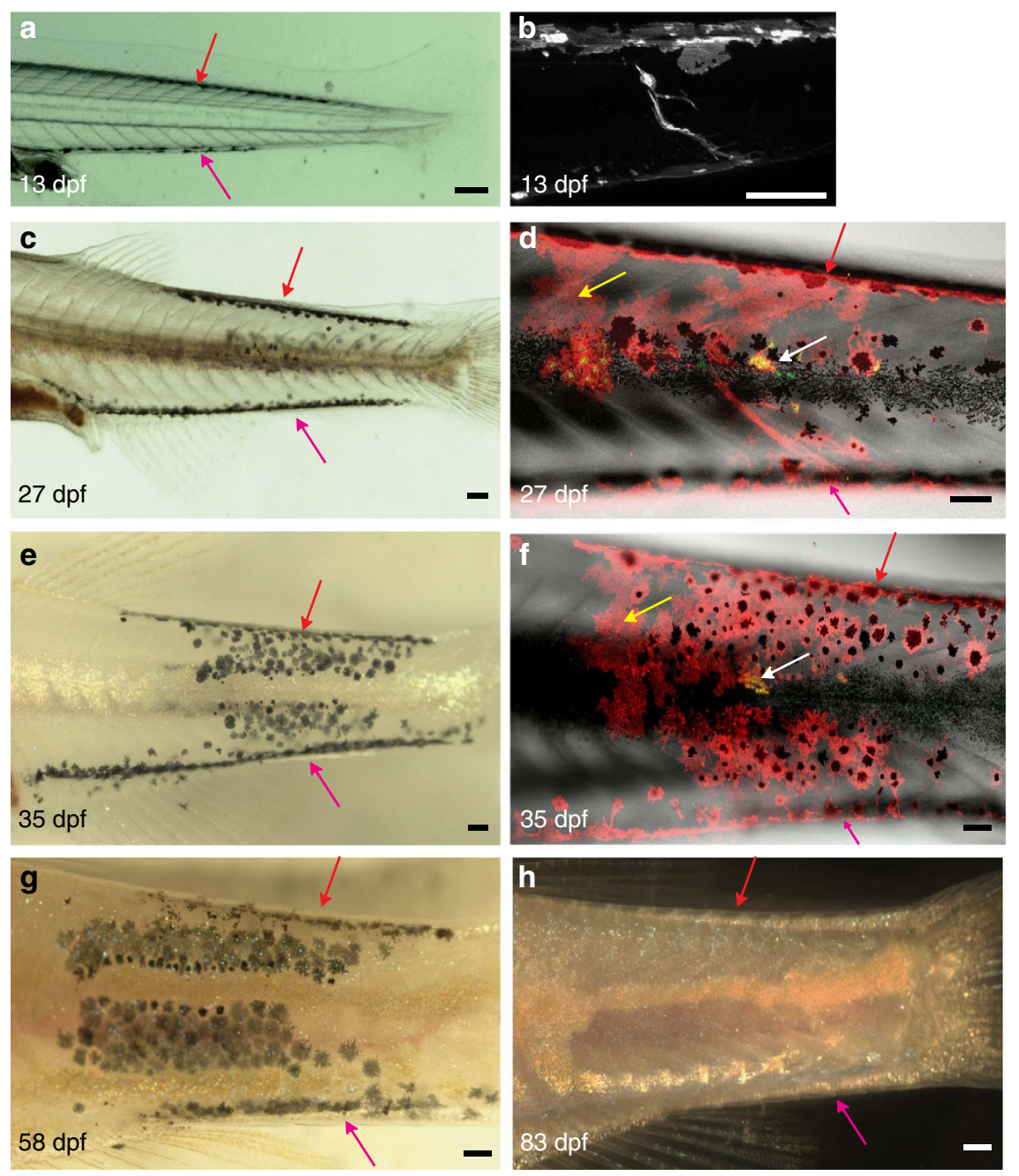

Figure 5 | Behaviour of melanophore clusters in nacre host. Clusters of wild-type melanophores (Tg(TDL358:GFP; sox10:mRFP)) in nacre followed through metamorphosis by $(\mathbf{a}, \mathbf{c}, \mathbf{e}, \mathbf{g}, \mathbf{h})$ bright-field microscopy and $(\mathbf{b}, \mathbf{d}, \mathbf{f})$ confocal imaging. (a-h): Dorsal and ventral streaks of melanophores are visible (red and pink arrows). These melanophores gradually disappear. (e-g) On 13 and $27 \mathrm{dpf}$ confocal microscopy shows a DRG labelled within the melanophore cluster. (b,d) Sox10:mRFP labels clusters of xanthophores (yellow arrows), (d,f) TDL358:GFP labels iridophores (white arrows). (e-g) The melanophore cluster extends over about six segments. (h) At $83 \mathrm{dpf}$ these melanophores disappear completely leaving a ghost dark stripe pattern surrounded by light stripes. Green plus red: iridophores, red only: xanthophores, red plus black: melanophores. Scale bars, a-h: $100 \mu \mathrm{m}$.

from $21 \mathrm{dpf}$ every $3-4$ days until $34 \mathrm{dpf}$ (Fig. 7). We observed that 4-6 segment large gaps were completely filled by iridophores coming from adjacent segments (Fig. 7a-e) and the pattern regenerated within 7-10 days (quantification in Fig. 7k). Large gaps $(\sim 10$ metameres on $21 \mathrm{dpf})$ were also filled in by spreading iridophores, but the recovery took longer (Fig. $7 \mathrm{f}-\mathrm{k}$ ). The striped pattern was not repaired perfectly resulting in wavy light and dark stripes on $34 \mathrm{dpf}$. In some cases $(n=7)$ we observed that iridophore clusters appeared in the middle of the gaps (white arrows in Fig. $7 \mathrm{~g}-\mathrm{i}$ ) spreading in all directions and resulting in a broader light stripe. In smaller gaps the cell number of melanophores in metameres recovered fully within 10 days yielding between 30 and 35 melanophores per metamere, the same number as compared to the control (the striped regions outside the gap) (Fig. 7l fish 1, 8; Supplementary Table 1), whereas in the bigger gaps on $34 \mathrm{dpf}$ the melanophore number was still lower $(<10$ melanophores per metamere Fig. 7l, fish 2, 3 and 4; Supplementary Table 1). In these larger gaps, only the segments adjacent to the striped region recovered significantly.

To visualize the behaviour of surviving iridophores and melanophores during pattern regeneration, we performed drugmediated ErbB inhibition on animals carrying $\operatorname{Tg}(\operatorname{sox} 10: m R F P)$ and imaged metamorphic fish (Figs 8, 9; Supplementary Fig. 5). Iridophores at the margins of the gaps migrate laterally, occupying iridophore-devoid regions of the prospective first light stripe (arrowheads in Fig. 8). Thus by proliferation and lateral dispersal, iridophores closed the gaps of 4-6 metamers completely within 10-12 days (graph in Fig. 7k). Iridophores at the margins of the gaps displayed the morphology of loose iridophores, and proliferated and migrated (Fig. 9a-c). Iridophores that are behind the migratory iridophores became densely packed and acquired the morphology of light stripe iridophores. In animals developing with large gaps $(\sim 10$ segments), occasionally regenerating iridophores could be seen in the middle of the gaps (Fig. $7 \mathrm{~g}$-i; Supplementary Fig. 5). These iridophore clusters were similar in size to iridophore clones originating from stem cells ${ }^{5}$, suggesting a regeneration potential for the progenitors.

Melanophores also regenerated from the margins of the gaps. Although a few melanophores displayed lateral movement (yellow arrow in Fig. 8c-g), most melanophores appeared de novo. This suggests that the new melanophores originate from unpigmented melanoblasts, which are regenerated by stem cells in the segments at the margins of the gaps. The melanophores exhibited limits in movement; in Fig. 8, three melanophores 

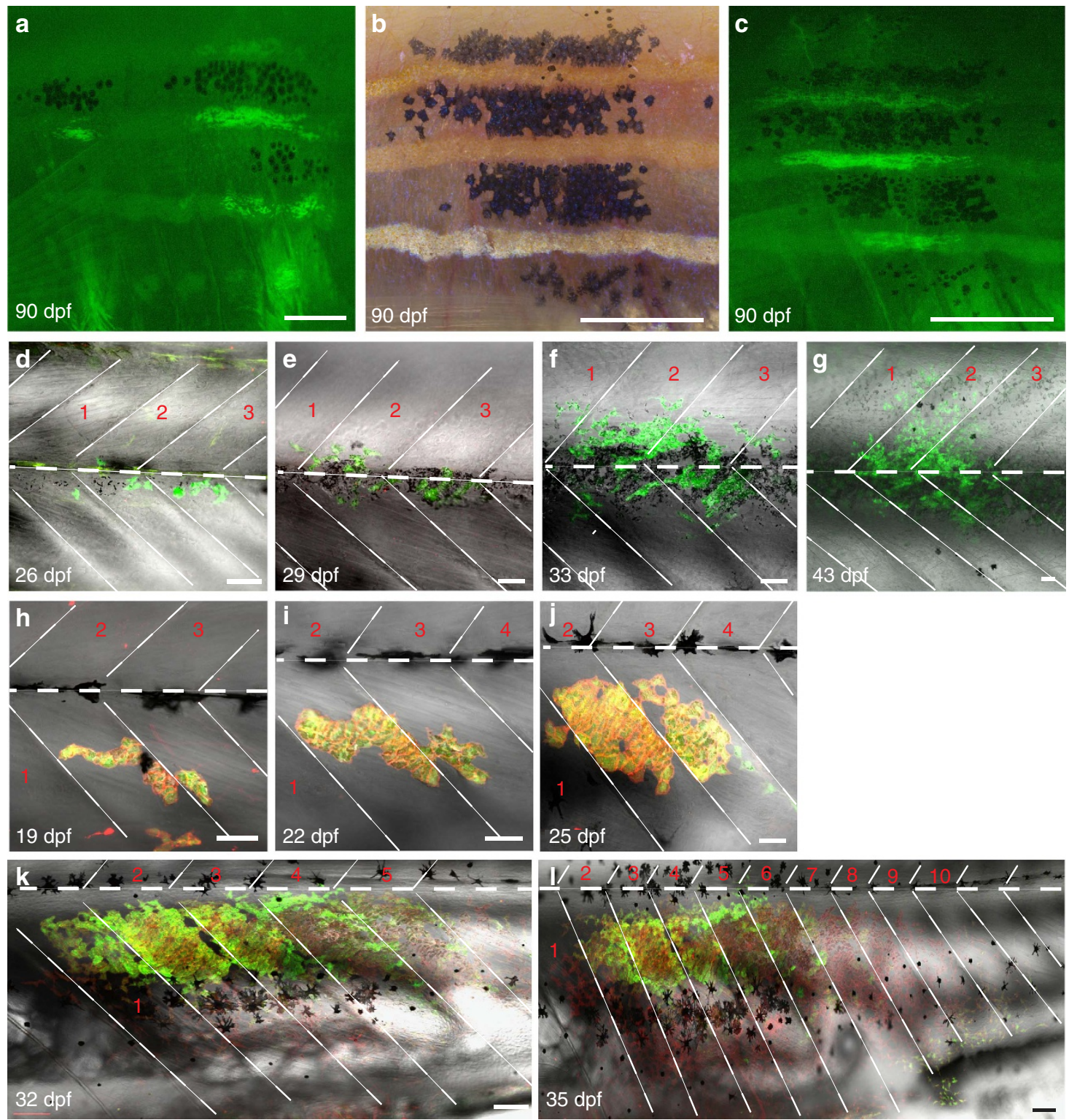

Figure 6 | Behaviour of iridophores in control (albino) and iridophore-deficient (shady) hosts. (a-c) Iridophore and melanophores clusters (derived from $\mathrm{Tg}($ (-act:GFP)) in control (albino) analysed with fluorescence (a,c) and bright-field microscopy (b): at $90 \mathrm{dpf}$ iridophores and melanophores cover several stripes spanning between 1 and 4 metameres. (d-g) Confocal images of (Tg(TDL358:GFP))-labelled iridophore clusters in control (albino): iridophores appear in three adjacent metameres at $26 \mathrm{dpf}$ and multiply within the same metameres. (h-I) (Tg(TDL358:GFP; sox10:mRFP)) cluster in shady covers 10 metameres at $35 \mathrm{dpf}$. Dashed white lines indicate vertical and horizontal myosepta. Red numbers indicate metameres. Scale bars, a-c: $250 \mu \mathrm{m}, \mathbf{d}-\mathbf{I}$ : $100 \mu \mathrm{m}$.

situated along the horizontal myoseptum (blue arrows in Fig. 8a-d), displayed short-scale movement towards the dorsal stripe region on the arrival of iridophores in the adjacent light stripe region. The ErbB inhibition did not affect xanthophores (Supplementary Fig. 5).

A closer analysis of developing animals that had a gap in the first light stripe, allowed us to study the formation of an interrupted stripe pattern (Fig. 9d-k). In an animal with an initial gap of six segments, five segments were filled by lateral migration of iridophores within 10 days (Fig. 9d-i). Interestingly, a break in the first light stripe $\mathrm{X} 0$ corresponded to a break in newly forming light stripe X1V (red arrowheads in Fig. 9i). This is consistent with a clonally-related origin of iridophores along the dorsoventral axis ${ }^{5}$. Some larval melanophores persisted in the gaps (red arrows in Fig. 9d-h), however, the melanophore numbers did not recover as fast as iridophores, leading to a melanophore-deprived region in the dark stripe (Fig. 9d,e). Subsequently, this melanophore-deprived region was invaded by iridophores from the first (X0) and the newly forming (X1V) light stripes, leading to interruptions of the dark stripe by light stripe regions (Fig. 9i-k). We conclude that the lateral spreading of the melanophores, in contrast to that of the iridophores is constrained.

Regeneration of xanthophores after cell-specific ablation. To test the regenerative potential of xanthophores, we ablated larval xanthophores at $5 \mathrm{dpf}$ by nitroreductase-mediated cell ablation ${ }^{29}$ in $T g(f m s: g a l 4 ; U A S: n f s B-m C h e r r y)$ larvae. To efficiently trace the xanthophores, they were carrying $\operatorname{Tg}($ pax7:GFP) (which also labels muscle stem cells). Following metronidazole treatment for $24 \mathrm{~h}$, nitroreductase expressing xanthophores were efficiently ablated without affecting the surrounding architecture 

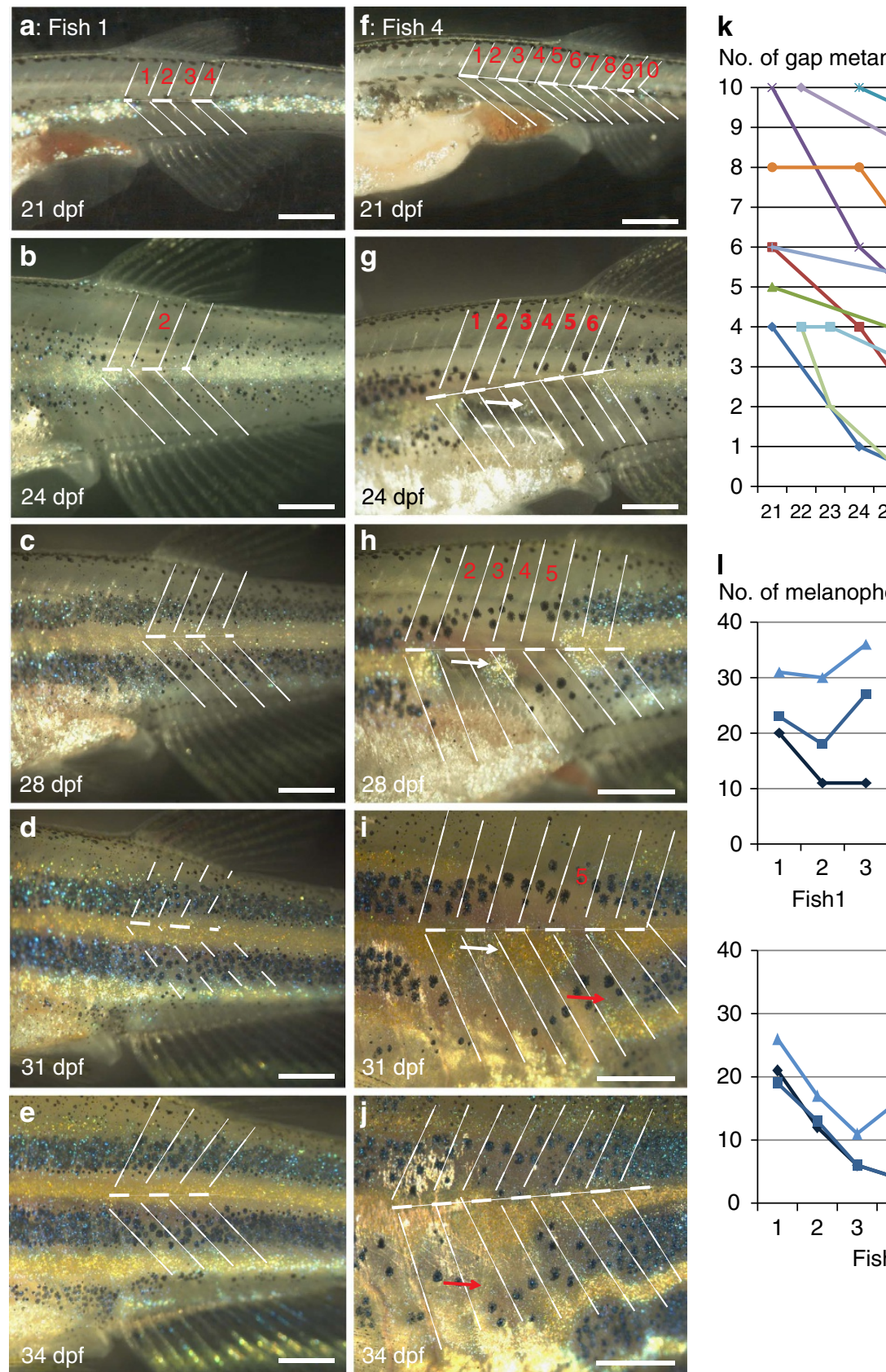

\section{k}

No. of gap metamers (iridophores)

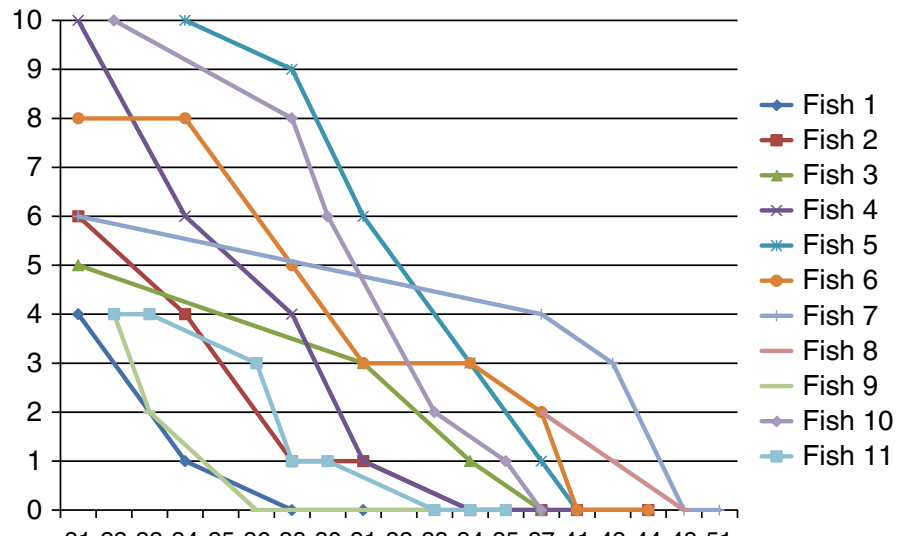

21222324252628303132333435374143444851

No. of melanophores in gap metamers
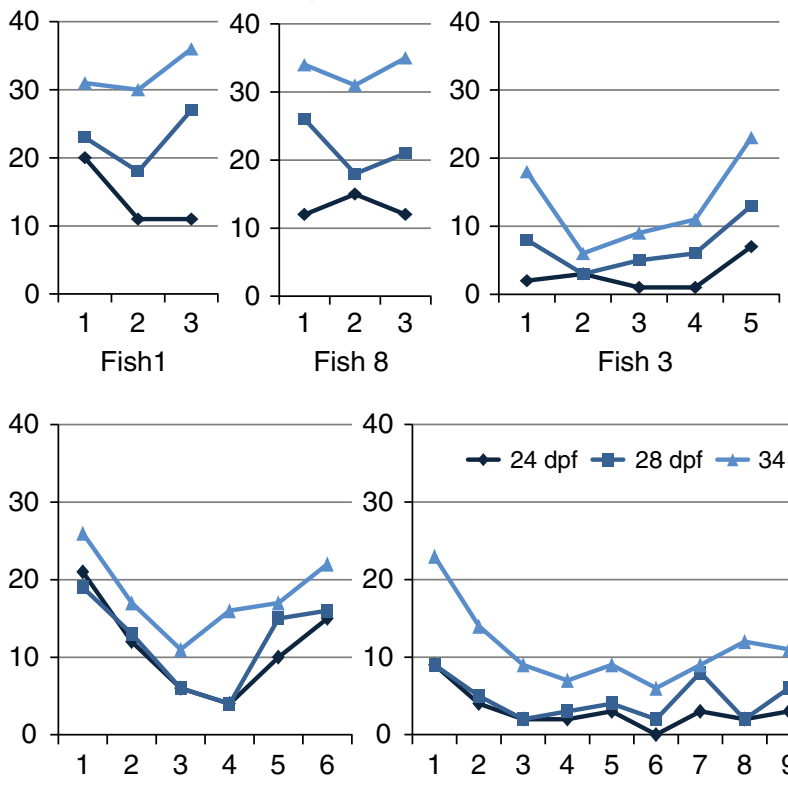

Fish 2

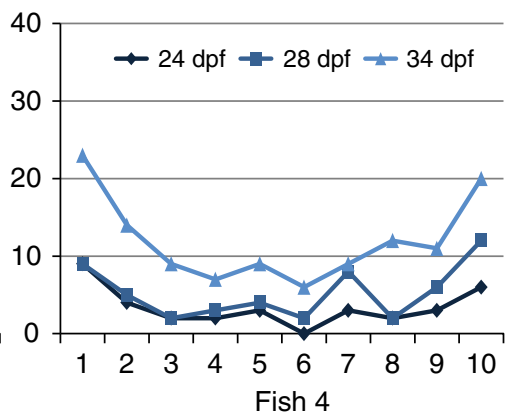

Figure 7 | Regeneration of iridophores and melanophores after ErbB inhibition. Treatment with PD168393 during embryogenesis (see methods) results in (a-j) gaps of different sizes (1-12 metamers) in the striped pattern of metamorphosing fish. Overall 15 fishes carrying gaps between 3 and 12 metamers were imaged through metamorphosis. Red numbers (a-i) indicate the segments that are devoid of iridophores at the onset of bright-field imaging. Dashed lines indicate vertical and horizontal myosepta. On $24 \mathrm{dpf}(\mathbf{g})$ a spot of regenerating iridophores appears in the middle of the gap and it expands laterally (white arrow in $\mathbf{g}, \mathbf{h}, \mathbf{i})$. (k) Time (in days) taken to fill the gaps of variable sizes in the stripe pattern. (I) Increase in numbers of melanophores in individual fish $(n=5)$ during regeneration of gap metamers at three different time points, 24,28 and $34 \mathrm{dpf}$. Scale bars, $\mathbf{a}-\mathbf{j}: 250 \mu \mathrm{m}$.

(Fig. 10 a-1). To visualize the extent of xanthophore regeneration, we tracked the ablated regions using confocal microscopy. By $10 \mathrm{dpf}$ regenerated green fluorescent protein (GFP)-labelled xanthophores could be observed in each segment. However, unexpectedly, regenerated xanthophores did not show the fms:gal4-mediated $n f s B-m C h e r r y$ expression, suggesting silencing of the transgene. When grown to adulthood, fish displayed a normal formation of the striped pattern indicating that xanthophores were fully restored (Fig. $10 \mathrm{~m}$ ). We suggest that the regeneration occurs from xanthophores originating from multipotent iridophore/melanophore stem cells ${ }^{5}$.

\section{Discussion}

The formation of the striped colour pattern in zebrafish involves several cell behaviours, including pigment-cell proliferation, dispersal and spatially controlled cell-shape transitions in the skin ${ }^{1,5,8,23}$. In this study, we find a role for homotypic competition in regulating pigment-cell proliferation, dispersal and tiling in the skin for all three chromatophore types. In the absence of competing cells within a layer in the skin, donor-derived clusters of xanthophores and iridophores proliferate at a faster rate than in their normal surrounding and cover larger regions of the skin. Mutant analysis indicates that 

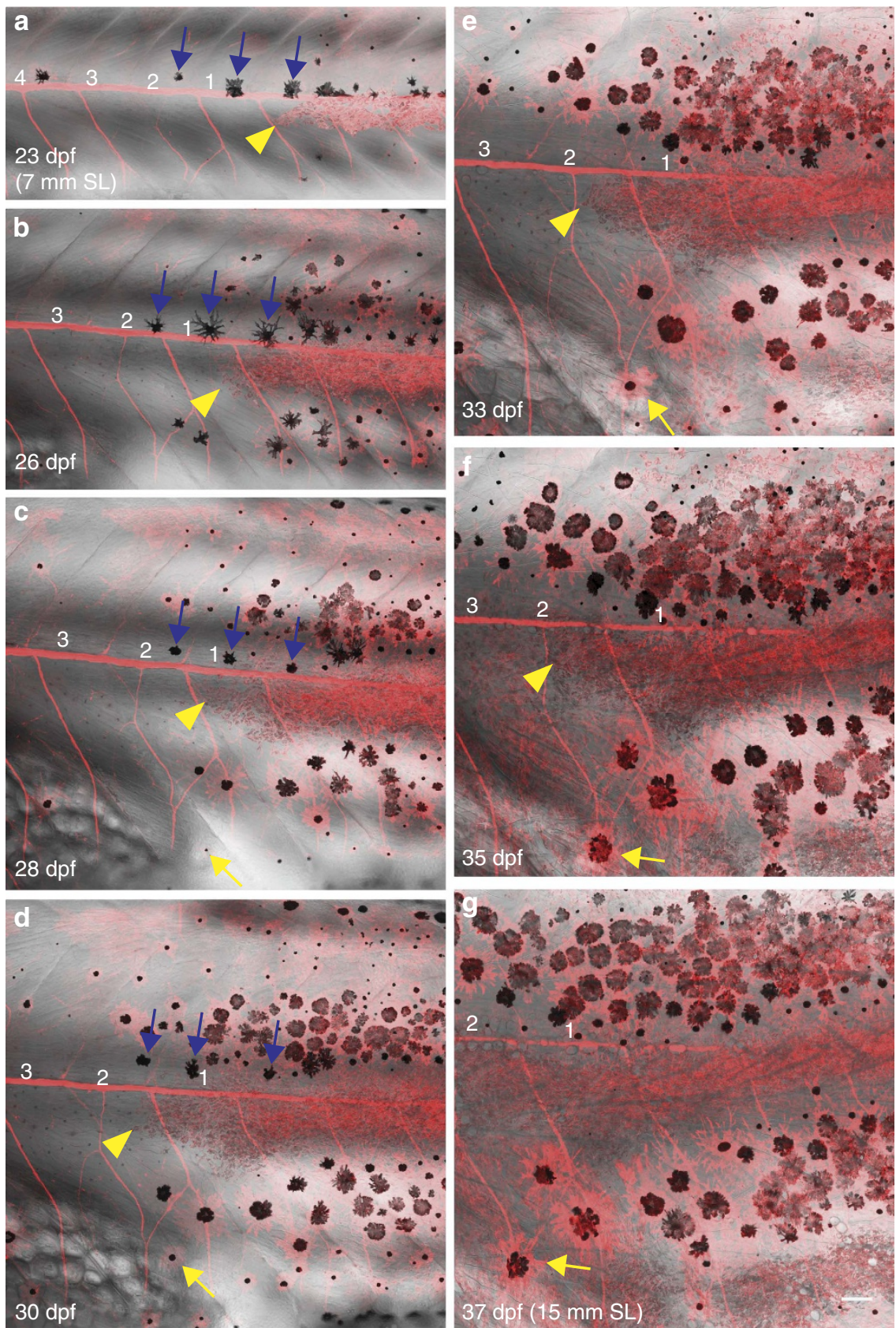

Figure 8 | Behaviour of iridophores and melanophores during pattern regeneration after ErbB inhibition. (a-g) Confocal images of $T g(s 0 x 10: m R F P$ ) animal developing with a gap (indicated by number 1-4) in the stripe pattern. Existing iridophores (yellow arrowheads) extend laterally into the prospective light stripe region that is devoid of iridophores and fill the region. New melanophores appear near the margins of the gap and locally restore the pattern. Occasionally, melanophores display short-scale movement (yellow arrows). Blue arrows: melanophores situated along the horizontal myoseptum that move dorsally to join dark stripes on regeneration of the light stripe by iridophores. Iridophores-red ( $T g(\operatorname{sox} 10: m R F P)$. SL, standard length of fish. Scale bars, $100 \mu \mathrm{m}$.

specification, proliferation and maintenance of pigment cells depend on individual receptor-ligand systems; Kit signalling for melanophores, Ednr and Ltk signalling for iridophores, and Csf1r signalling for xanthophores $12,94-16,30-32$. Whereas the pigment cells express the respective receptor, the ligands are presumably functioning as trophic factors produced by surrounding tissue. Competition for the ligands may in part be responsible for the regulation of pigment-cell proliferation in normal development.

Competitive interactions among pigment cells result in an overall directionality in the pigment-cell migration that determines the dorsoventrally orientated clonal expansion of the pigment cells. During normal development, in the presence of pigment cells of the same type, clusters of all three pigment-cell types spread in dorsoventral direction as the fish grows ((ref. 5); Fig. 6a-c; Supplementary Figs 1, 2). The clusters contributed to most if not all stripes in a narrow patch along the dorsoventral axis. Spreading along the anteroposterior direction was less pronounced, and the clusters contributed to between 1 and 4 adjacent segments. This reveals that in normal development, the pattern is stitched together by adjacent clones derived from stem cells at the DRG of neighbouring metamers (iridophores and melanophores), and from larval xanthophores. 

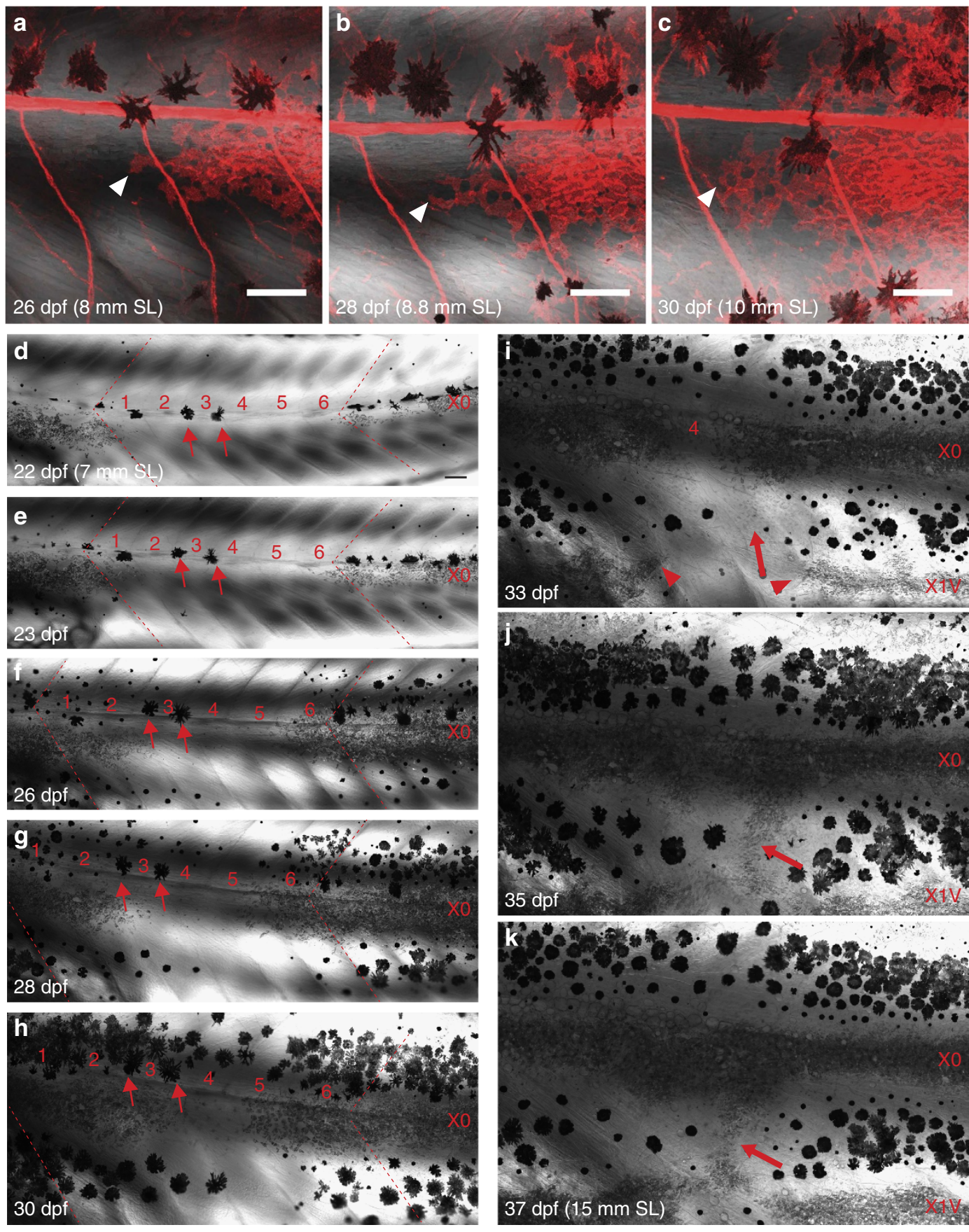

Figure 9 | Iridophore disperse laterally to occupy iridophore-devoid regions. (a-c) Iridophores (white arrowheads, $\operatorname{Tg}($ sox $10: m R F P)$ ) extend to the empty segment on the left and increase in number. (d-k) Gap closure in an animal lacking iridophores in six segments at 22 dpf (numbered 1-6). Red dashed lines indicate the original borders of the gap. Small arrows in $\mathbf{d}-\mathbf{h}$ : larval melanophores remain stable within the gap. (e) Iridophores that are present outside the gap begin to invade the iridophore-devoid segments and within a day, iridophores can be seen in segment 1 and 6 . (f-h) By lateral movement, iridophores recover in segments 1-3 and 5-6, only the segment 4 remains devoid of iridophores. (i) The first light stripe, XO lacks iridophores in the segment 4 and remains interrupted. Corresponding region in the newly formed light stripe also lacks iridophores (red arrowheads). The dark stripe region does not develop sufficient melanophores and subsequently iridophores begin to migrate vertically (big red arrow) invading the dark stripe region. (j,k) Vertically migrating iridophores lead to interruption of the dark stripe region by the light stripe region. SL, standard length of fish. Scale bars, $100 \mu \mathrm{m}$.

The lateral extension of the clones is restricted by homotypic competition. Thus, the dorsoventral orientation of the pigmentcell clones observed in normal development is the result of competitive interactions between cells from neighbouring segments and not the product of a hypothetical, morphogen-based directed migration.

As reported earlier ${ }^{12,18}$, the introduction of the missing cell type into mutants lacking a given pigment-cell type locally restores a normal pattern. The incoming cells in the spreading clusters induce cell-shape changes in the adjacent cell layers such that a normal stripe pattern is formed while the clusters grow. This involves extensive shape changes in the pigment cells of the host as well as the donor. Our high-resolution images confirm that there is a constant adjustment with mutual interactions between the three cell types during stripe formation. In conclusion, heterotypic interactions between the three layers 

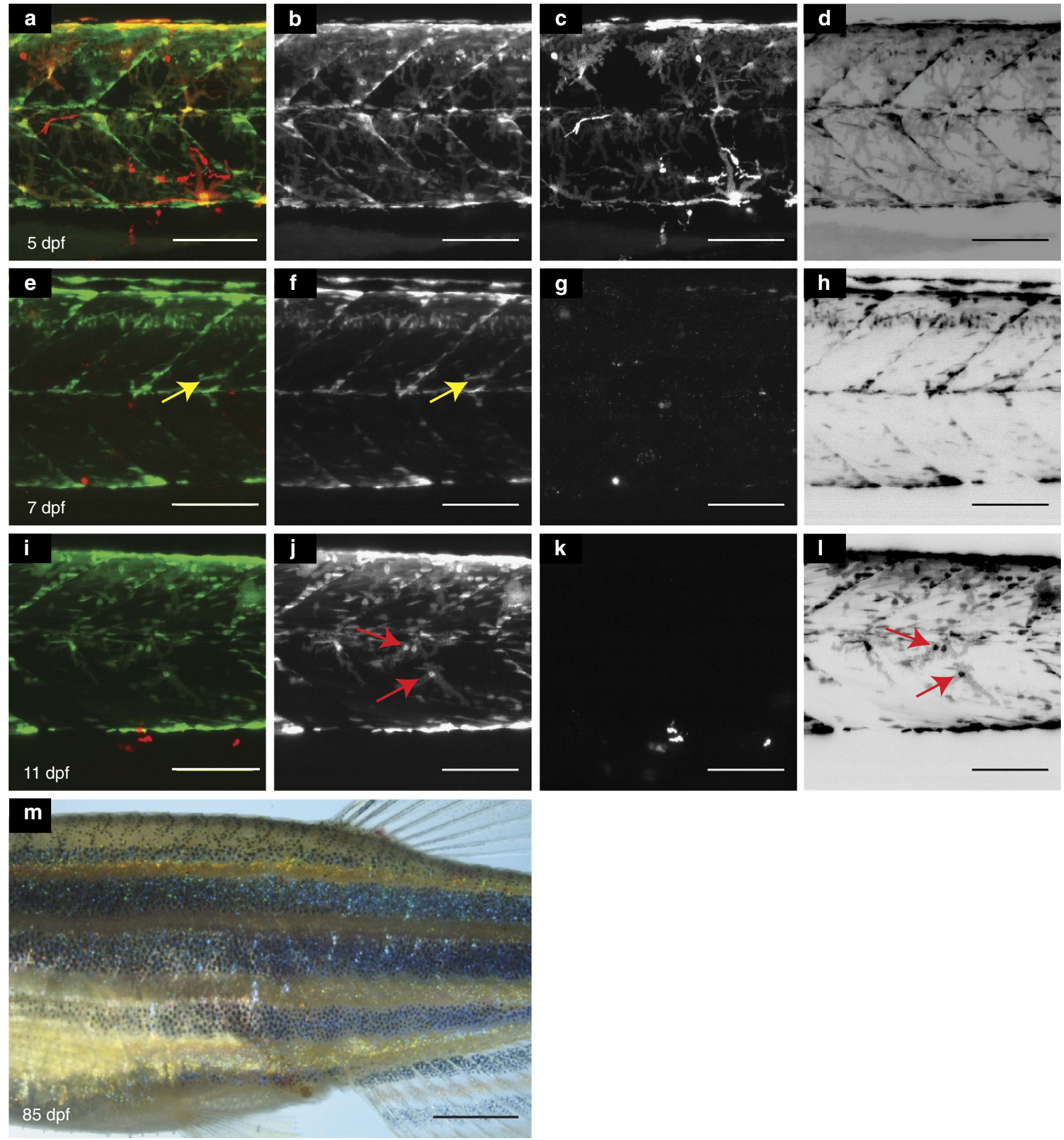

Figure 10 | Xanthophore regeneration following drug-mediated ablation. (a-d): Larva at $5 \mathrm{dpf}$, xanthophores: $g r e e n$ ( $\operatorname{Tg}(\mathrm{pax} 7: G F P)$ and red: $\operatorname{Tg}(f m s: G a l 4$, UAS:nfsB-mcherry). (e-h): The same region after ablation at $7 \mathrm{dpf:} \mathrm{yellow} \mathrm{arrow:} \mathrm{(Tg(pax7:GFP)} \mathrm{labels} \mathrm{muscle} \mathrm{tissue} \mathrm{and} \mathrm{their} \mathrm{precursors}{ }^{24}$. (i-I): same region at $11 \mathrm{dpf}$. Red arrow: regenerated xanthophore. (a,e,i): merge; (b,f,j): (Tg(pax7:GFP) in grey scale; (c,g,k): $\operatorname{Tg}(f m s: G a l 4, U A S: n f s B-m c h e r r y)$ in grey scale; $(\mathbf{d}, \mathbf{h}, \mathbf{I}):(\operatorname{Tg}($ pax7:GFP) in inverted grey scale. (m): Adult fish after ablation displaying a normal pattern. Scale bars, a-I: $100 \mu \mathrm{m}, \mathbf{m :} 250 \mu \mathrm{m}$.

regulate cell-shape transition, whereas the homotypic interactions we observe regulate pigment-cell dispersal in a coherent twodimensional sheet within one layer.

Strikingly, in adult chimeras, the patches of donor-derived pigment cells are coherent and have normal densities. This indicates that there is an intrinsic tendency for pigment cells to remain together observing normal distances, rather than dispersing into regions devoid of their cell type. We suggest that the cell-cell interactions are mediated by direct cellular contacts.
Live-imaging of the behaviour of xanthophores in larvae (Fig. 3) shows that xanthophores maintain a dynamic contact with one another, and proliferate in the absence of neighbouring xanthophores. The xanthophore filopodia are highly dynamic actin-rich protrusions ${ }^{33}$, which may allow xanthophores to probe their environment and contact neighbouring xanthophores, thus maintaining a sheet-like xanthophore cover in the skin through cell division and migration into xanthophore-devoid regions. In the growing skin, increasing the distances between neighbouring 
xanthophores may trigger cell divisions such that a regular spacing is maintained.

Iridophores spreading in shady chimeras, or laterally migrating into gaps devoid of iridophores also acquire a loose migratory shape but stay in direct contact with one another rather than dispersing. This behaviour is also observed in normal development in which iridophores during metamorphosis populate the skin as a loose net of interconnected cells spreading dorsally and ventrally ${ }^{5}$.

The melanophores in stripes formed in nacre chimeras also maintain normal distances to one another. In normal development, melanophores extend long cytoplasmic protrusions allowing them to contact each other while filling in the dark stripe region ${ }^{5}$. This suggests that the spacing of melanophores in the stripes is mediated by direct cell contacts between melanophores. Mutant analyses, however, indicate in addition a strong dependence of melanophore spacing on heterotypic interactions, in particular with xanthophores, whereas iridophores and xanthophores display a more autonomous behaviour ${ }^{12}$.

The responses of pigment cells to homotypic interactions, in particular those observed in xanthophores and iridophores, resemble that of neural crest cells, which undergo collective cell migration and display co-attraction despite contact inhibition of locomotion $^{34}$. Contact inhibition of locomotion is a longestablished phenomenon observed in cultured cells in vitro ${ }^{35-38}$, and more recently in vivo ${ }^{39-41}$. It is suggested that co-attraction and contact inhibition of locomotion act in concert orchestrating collective migration of neural crest cells-contact inhibition of locomotion alone would lead to dispersal of the group into single cells ${ }^{40}$. Co-attraction, in combination with contact inhibition of locomotion allows maintenance of appropriate cell density, local homotypic cell-cell interactions and efficient response to external cues. We hypothesize similar interactions between pigment cells of the same kind during pattern formation-clusters of wild-type xanthophores do not disperse into single cells in absence of xanthophores in the neighbourhood. Instead, these cells maintain appropriate local cell density while the cluster grows by local proliferation and short-scale movement. This is also true for iridophores and melanophores suggesting co-attraction and contact inhibition of locomotion may underlie pigment-cell coverage by homotypic interactions in the skin. Our knowledge of the molecular bases of cell contact-mediated interactions during colour pattern formation is still rudimentary. At the molecular level, interactions between chromatophores have been shown to depend on integral membrane proteins including connexins and potassium channels, suggesting that physical cell contacts between chromatophores are involved and that the directed transport of small molecules or bioelectrical coupling are important for these interactions ${ }^{21,22,42}$. In obelix, encoding the inwardly rectifying potassium channel Kir7.1, melanophore stripes are enlarged, with a lower than normal density of melanophores ${ }^{18,43}$. This channel is specifically required in melanophores and may be responsible for their proper spacing. The gap junctions formed by the connexins encoded by the leopard and luchs genes have been suggested to mediate heterotypic as well as homotypic interactions among melanophores and xanthophores ${ }^{18,22,44}$. Connexins mediate intercellular communication that may lead to diverse cellular outcomes including oriented cell migration ${ }^{45}$. The Immunoglobulin Superfamily Member 11, mutated in seurat, has been reported to mediate aspects of melanophore behaviour including melanophore-melanophore interactions ${ }^{46}$. It is conceivable that connexins and other cell-surface molecules mediate the homotypic competition-dependent proliferation and tiling of the pigment cells. Our experimental paradigm provides an opportunity to assess the molecular regulation of the cellular outcomes of the diverse cell-cell interactions during colour pattern formation.

\section{Methods}

Zebrafish lines. The following zebrafish lines were used: wild-type (WT, Tübingen strain $^{47}$ from the Tübingen zebrafish stock centre), albino ${ }^{25}$, nacre ${ }^{13}$, pfeffer $^{18}$, brass $^{27}$, shady $^{16,27}, \mathrm{Tg}(\text { fms:Gal4, UAS:mcherry })^{48}, \mathrm{Tg}(\text { pax7:GFP })^{8,24}$, $\operatorname{Tg}(T D L 358: G F P)^{49}, \operatorname{Tg}(\operatorname{sox} 10: m R F P)^{5}, \operatorname{Tg}(\beta a c t i n 2: G F P)$. Zebrafish were raised as $\operatorname{described}^{50}$. The staging of metamorphic fish was done as described ${ }^{12,51}$. All animal experiments were performed in accordance with the rules of the State of Baden-Württemberg, Germany and approved by the Regierungspräsidium Tübingen.

Blastomere transplantation. Chimeric animals were generated by transplantation of cells of appropriately labelled blastula stage embryos into wild type and mutant embryos at blastula stage ${ }^{52}$. The number of transplanted cells was monitored using Rhodamine dextran injected in the donor embryos at the one cell stage, and the number of transplanted cells was estimated to be in the range between 1-10 cells Fishes were raised and analysed at different time points throughout metamorphosis until adulthood.

Pharmacological inhibition of the ErbB signalling pathway. The ErbB inhibitor treatment was done as described previously ${ }^{6}$. In brief, 14 somite stage embryos were treated with $10 \mu \mathrm{M}$ ErbB inhibitor (PD168393) dissolved in E2 for $5 \mathrm{~h}$ at $29^{\circ} \mathrm{C}$. The ErbB inhibitor phenotype is similar to that of erbb3b (hypersensitive/ picasso) mutants ${ }^{6,28}$ : during the early stages of metamorphosis the fish develop with regions in the prospective light and dark stripe regions without iridophores and melanophores. Wild-type animals at corresponding stages display contiguous light and dark stripes. We term the melanophore and iridophore-devoid regions as "gaps". The size of these gaps along the AP axis is variable in both, the erbb3b mutants and the ErbB inhibitor-treated animals.

Genetically-targeted ablation of xanthophores. Targeted ablation of xanthophores was performed as described ${ }^{29}$. In brief, larvae carrying $T g(f m s: G a l 4$ $\mathrm{Tg}\left(U A S: n f_{s} B-m\right.$ cherry $\left.)\right)^{48}$ were treated with metronidazole for $24 \mathrm{~h}$ at $5 \mathrm{dpf}$. This results in targeted ablation of xanthophores. $\operatorname{Tg}(\operatorname{pax} 7: G F P)^{8,24}$, a reporter line that labels xanthophores, muscles and muscle progenitors, was used for xanthophore visualization. Xanthophores can be recognized by their characteristic shape and location in the skin. The first imaging of the larvae was done immediately before the drug treatment. Subsequent imaging was done as mentioned in the text.

Image acquisition and processing. Repeated imaging of zebrafish was performed as described ${ }^{5}$. Images were acquired on Zeiss LSM 780 NLO confocal and Leica M205 FA stereo-microscopes. Image ${ }^{53}$, Adobe Photoshop, Adobe Illustrator and Imaris were used for image processing and analysis. Maximum intensity projections of confocal scans of the fluorescent samples were uniformly adjusted for brightness and contrast. Scans of the bright field were stacked using "stack focuser" plugin and tile scans were stitched in Fiji ${ }^{4}$.

\section{References}

1. Singh, A. P. \& Nüsslein-Volhard, C. Zebrafish stripes as a model for vertebrate colour pattern formation. Curr. Biol. 25, R81-R92 (2015).

2. Irion, U, Singh, A. P. \& Nüsslein-Volhard, C. The developmental genetics of vertebrate colour pattern formation: lessons from zebrafish. Curr. Top. Dev. Biol. 117, 141-169 (2016).

3. Watanabe, $\mathrm{M} \&$ Kondo, S. Is pigment patterning in fish skin determined by the Turing mechanism? Trends Genet. 31, 88-96 (2015).

4. Parichy, D. M. \& Spiewak, J. E.. Origins of adult pigmentation: diversity in pigment stem cell lineages and implications for pattern evolution. Pigment Cell Melanoma Res. 28, 31-50 (2015).

5. Singh, A. P., Schach, U \& Nüsslein-Volhard, C. Proliferation, dispersal and patterned aggregation of iridophores in the skin prefigure striped colouration of zebrafish. Nat. Cell. Biol. 16, 607-614 (2014).

6. Dooley, C. M., Mongera, A, Walderich, B \& Nüsslein-Volhard, C. On the embryonic origin of adult melanophores: the role of ErbB and Kit signalling in establishing melanophore stem cells in zebrafish. Development 140, 1003-1013 (2013).

7. Budi, E. H., Patterson, L. B. \& Parichy, D. M.. Post-embryonic nerve-associated precursors to adult pigment cells: genetic requirements and dynamics of morphogenesis and differentiation. PLoS Genet. 7, e1002044 (2011).

8. Mahalwar, P, Walderich, B, Singh, A. P. \& Nüsslein-Volhard, C. Local reorganization of xanthophores fine-tunes and colors the striped pattern of zebrafish. Science 345, 1362-1364 (2014).

9. McMenamin, S. K. et al. Thyroid hormone-dependent adult pigment cell lineage and pattern in zebrafish. Science 345, 1358-1361 (2014). 
10. Hirata, M, Nakamura, K, Kanemaru, T, Shibata, Y \& Kondo, S. Pigment cell organization in the hypodermis of zebrafish. Dev. Dyn. 227, 497-503 (2003).

11. Hirata, M, Nakamura, K \& Kondo, S. Pigment cell distributions in different tissues of the zebrafish, with special reference to the striped pigment pattern. Dev. Dyn. 234, 293-300 (2005).

12. Frohnhöfer, H. G., Krauss, J, Maischein, H. M. \& Nüsslein-Volhard, C. Iridophores and their interactions with other chromatophores are required for stripe formation in zebrafish. Development 140, 2997-3007 (2013).

13. Lister, J. A., Robertson, C. P., Lepage, T, Johnson, S. L. \& Raible, D. W.. nacre encodes a zebrafish microphthalmia-related protein that regulates neural-crestderived pigment cell fate. Development 126, 3757-3767 (1999).

14. Parichy, D. M. et al. Mutational analysis of endothelin receptor b1 (rose) during neural crest and pigment pattern development in the zebrafish Danio rerio. Dev. Biol. 227, 294-306 (2000).

15. Parichy, D. M., Ransom, D. G., Paw, B, Zon, L. I. \& Johnson, S. L.. An orthologue of the kit-related gene fms is required for development of neural crest-derived xanthophores and a subpopulation of adult melanocytes in the zebrafish, Danio rerio. Development 127, 3031-3044 (2000).

16. Lopes, S. S. et al. Leukocyte tyrosine kinase functions in pigment cell development. PLoS Genet. 4, e1000026 (2008).

17. Krauss, J, Astrinides, P, Frohnhöfer, H. G., Walderich, B \& Nüsslein-Volhard, C. transparent, a gene affecting stripe formation in zebrafish, encodes the mitochondrial protein Mpv17 that is required for iridophore survival. Biol. Open 2, 703-710 (2013).

18. Maderspacher, F \& Nüsslein-Volhard, C. Formation of the adult pigment pattern in zebrafish requires leopard and obelix dependent cell interactions. Development 130, 3447-3457 (2003).

19. Nakamasu, A, Takahashi, G, Kanbe, A \& Kondo, S. Interactions between zebrafish pigment cells responsible for the generation of Turing patterns. Proc. Natl Acad. Sci. USA 106, 8429-8434 (2009).

20. Singh, A. P., Frohnhöfer, H. G., Irion, U \& Nüsslein-Volhard, C. Fish pigmentation. response to comment on "Local reorganization of xanthophores fine-tunes and colors the striped pattern of zebrafish". Science 348, 297 (2015).

21. Yamanaka, H \& Kondo, S. In vitro analysis suggests that difference in cell movement during direct interaction can generate various pigment patterns in vivo. Proc. Natl Acad. Sci. USA 111, 1867-1872 (2014).

22. Irion, $\mathrm{U}$ et al. Gap junctions composed of connexins 41.8 and 39.4 are essential for colour pattern formation in zebrafish. Elife 3, e05125 (2014).

23. Fadeev, A, Krauss, J, Fröhnhofer, H. G., Irion, U \& Nüsslein-Volhard, C. Tight junction protein 1a regulates pigment cell organisation during zebrafish colour patterning. Elife 4, e06545 (2015).

24. Alsheimer, S. On Teleost Muscle Stem Cells and the Vertical Myoseptum as their Niche 1-249 PhD Dissertation, Eberhard-Karls-Univ. (2012).

25. Dooley, C. M. et al. Slc45a2 and V-ATPase are regulators of melanosomal pH homeostasis in zebrafish, providing a mechanism for human pigment evolution and disease. Pigment Cell Melanoma Res. 26, 205-217 (2013).

26. Kelsh, R. N. et al. Zebrafish pigmentation mutations and the processes of neural crest development. Development 123, 369-389 (1996).

27. Haffter, $\mathrm{P}$ et al. Mutations affecting pigmentation and shape of the adult zebrafish. Dev. Genes. Evol. 206, 260-276 (1996).

28. Budi, E. H., Patterson, L. B. \& Parichy, D. M.. Embryonic requirements for ErbB signaling in neural crest development and adult pigment pattern formation. Development 135, 2603-2614 (2008).

29. Pisharath, H \& Parsons, M. J.. Nitroreductase-mediated cell ablation in transgenic zebrafish embryos. Methods Mol. Biol. 546, 133-143 (2009).

30. Parichy, D. M., Rawls, J. F., Pratt, S. J., Whitfield, T. T. \& Johnson, S. L.. Zebrafish sparse corresponds to an orthologue of c-kit and is required for the morphogenesis of a subpopulation of melanocytes, but is not essential for hematopoiesis or primordial germ cell development. Development 126, 34253436 (1999).

31. Krauss, J et al. Endothelin signalling in iridophore development and stripe pattern formation of zebrafish. Biol. Open 3, 503-509 (2014).

32. Fadeev, A, Krauss, J, Singh, A. P. \& Nüsslein-Volhard, C. Zebrafish leukocyte tyrosine kinase controls iridophore establishment, proliferation and survival. Pigment Cell Melanoma Res. http://dx.doi.org/10.1111/pcmr.12454 (2016).

33. Panza, P, Maier, J, Schmees, C, Rothbauer, U \& Sollner, C. Live imaging of endogenous protein dynamics in zebrafish using chromobodies. Development 142, 1879-1884 (2015).

34. Mayor, R \& Theveneau, E. The neural crest. Development 140, 2247-2251 (2013).

35. Martz, E \& Steinber, M.S. Role of cell-cell contact in contact inhibition of celldivision-review and new evidence. J. Cell. Physiol. 79, 189-210 (1972).

36. Abercrombie, M. Contact inhibition in tissue culture. In Vitro Cell Dev. B 6, 128 (1970).

37. Abercrombie, M \& Heaysman, J. E.. Observations on the social behaviour of cells in tissue culture. I. Speed of movement of chick heart fibroblasts in relation to their mutual contacts. Exp. Cell. Res. 5, 111-131 (1953).
38. Abercrombie, M \& Heaysman, J. E.. Observations on the social behaviour of cells in tissue culture. II. Monolayering of fibroblasts. Exp. Cell. Res. 6, 293-306 (1954).

39. Carmona-Fontaine, $\mathrm{C}$ et al. Contact inhibition of locomotion in vivo controls neural crest directional migration. Nature 456, 957-961 (2008).

40. Carmona-Fontaine, $\mathrm{C}$ et al. Complement fragment C3a controls mutual cell attraction during collective cell migration. Dev. Cell. 21, 1026-1037 (2011).

41. Davis, J. R. et al. Inter-cellular forces orchestrate contact inhibition of locomotion. Cell 161, 361-373 (2015).

42. Inaba, M, Yamanaka, $\mathrm{H} \&$ Kondo, S. Pigment pattern formation by contactdependent depolarization. Science 335, 677 (2012).

43. Iwashita, $\mathrm{M}$ et al. Pigment pattern in jaguar/obelix zebrafish is caused by a Kir7.1 mutation: implications for the regulation of melanosome movement. PLoS Genet. 2, e197 (2006).

44. Watanabe, $\mathrm{M}$ et al. Spot pattern of leopard Danio is caused by mutation in the zebrafish connexin41.8 gene. EMBO Rep. 7, 893-897 (2006).

45. Kotini, M \& Mayor, R. Connexins in migration during development and cancer. Dev. Biol. 401, 143-151 (2015).

46. Eom, D. S. et al. Melanophore migration and survival during zebrafish adult pigment stripe development require the immunoglobulin superfamily adhesion molecule Igsf11. PLoS Genet. 8, e1002899 (2012).

47. Haffter, $\mathrm{P}$ et al. The identification of genes with unique and essential functions in the development of the zebrafish, Danio rerio. Development 123, 1-36 (1996).

48. Gray, C et al. Simultaneous intravital imaging of macrophage and neutrophil behaviour during inflammation using a novel transgenic zebrafish. Thromb. Haemost. 105, 811-819 (2011).

49. Levesque, M. P., Krauss, J, Koehler, C, Boden, C \& Harris, M. P.. New tools for the identification of developmentally regulated enhancer regions in embryonic and adult zebrafish. Zebrafish 10, 21-29 (2013).

50. Brand, M, Granato, M \& Nüsslein-Volhard, C. in Keeping and Raising Zebrafish. Zebrafish, Practical Approach. Ch. 1, 7-37 (Oxford Univ. Press, 2002).

51. Parichy, D. M., Elizondo, M. R., Mills, M. G., Gordon, T. N. \& Engeszer, R. E. Normal table of postembryonic zebrafish development: staging by externally visible anatomy of the living fish. Dev. Dyn. 238, 2975-3015 (2009).

52. Kane, D. A. \& Kishimoto, Y. in Cell Labelling And Transplantation Techniques. Zebrafish, Practical Approach. Ch. 4, 95-119 (Oxford Univ. Press, 2002).

53. Schneider, C. A., Rasband, W. S. \& Eliceiri, K. W.. NIH Image to ImageJ: 25 years of image analysis. Nat. Methods 9, 671-675 (2012).

54. Preibisch, S, Saalfeld, S \& Tomancak, P. Globally optimal stitching of tiled 3D microscopic image acquisitions. Bioinformatics 25, 1463-1465 (2009).

\section{Acknowledgements}

We thank Darren Gilmour, Patrick Müller, Uwe Irion, Hans-Georg Frohnhöfer, April Dinwiddie, Anastasia Eskova and Andrey Fadeev for comments on the manuscript. We thank Andrey Fadeev for help with the bright-field imaging of adult fish. This work was supported by the Max Planck Society.

\section{Author contributions}

B.W., A.P.S. and C.N.V. conceived and designed the experiments; B.W. performed the blastomere transplantations; A.P.S. analysed the regeneration on depletion of stem cells and P.M. the drug-mediated xanthophore ablation experiment. A.P.S. and P.M. provided confocal images of the chimeras. C.N.V., B.W. and A.P.S. wrote the paper.

\section{Additional information}

Supplementary Information accompanies this paper at http://www.nature.com/ naturecommunications

Competing financial interests: The authors declare no competing financial interests

Reprints and permission information is available online at http://npg.nature.com/ reprintsandpermissions/

How to cite this article: Walderich, B. et al. Homotypic cell competition regulates proliferation and tiling of zebrafish pigment cells during colour pattern formation. Nat. Commun. 7:11462 doi: 10.1038/ncomms11462 (2016).

This work is licensed under a Creative Commons Attribution 4.0 International License. The images or other third party material in this article are included in the article's Creative Commons license, unless indicated otherwise in the credit line; if the material is not included under the Creative Commons license, users will need to obtain permission from the license holder to reproduce the material. To view a copy of this license, visit http://creativecommons.org/licenses/by/4.0/ 